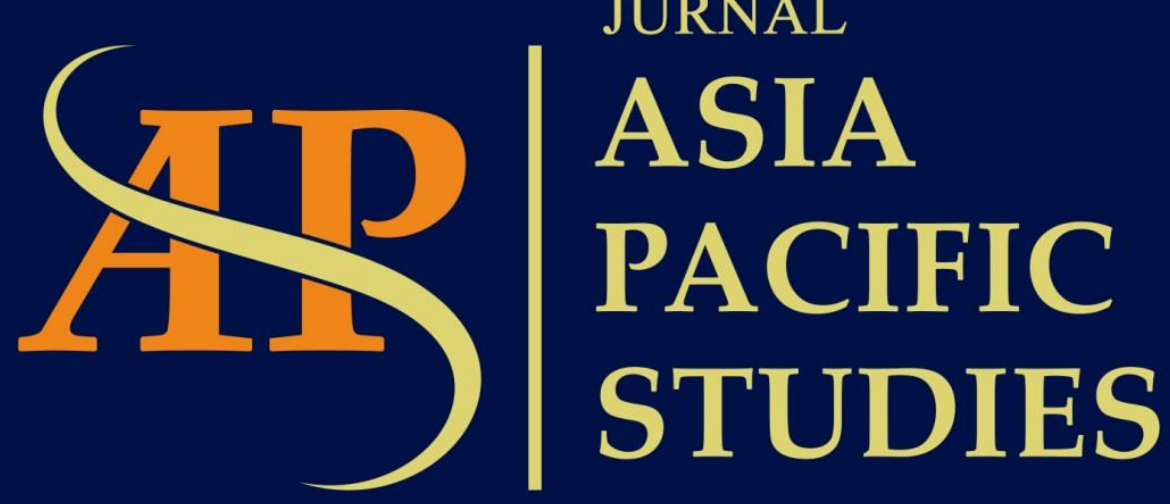

Journal of International Relations Study Program Faculty of Social and Political Sciences Universitas Kristen Indonesia

Volume 3 | Number 1 | January - June 2019 


\title{
FENOMENA INDO-PASIFIK DAN DIPLOMASI INDONESIA
}

\author{
V.L. Sinta Herindrasti \\ Hubungan Internasional, Fakultas Ilmu Sosial dan Ilmu Politik Universitas Kristen Indonesia, Jalan \\ Mayjen Sutoyo No.2, Jakarta Timur, Daerah Khusus Ibukota Jakarta 13630, Indonesia \\ Herindrasti@yahoo.com
}

\begin{abstract}
The emergence of the Indo-Pacific terminology since 2007 until 2013, which is still growing stronger up until now, has created a new "tension" dynamic among various actors in the region. The term Indo-Pacific at least reflects the exisiting new geopolitics transformation discourse in the regions between Indian and Pacific Oceans. With its strategic position, Indonesia is also active in the development of Indo-Pacific's discourse and diplomacy. Considering the broad geographical area coverage of the Indo-Pacific concept and various stateactors including involvement of their power distribution and structure, comprehensive and critical analysis of Indo-Pacific phenomenon observation are therefore required. What is the purpose of Indonesia through its IndoPacific diplomatic action? Are there any current urgent needs which warrant involvement in these broad geopolitical issues? Does Indo-Pacific answer the needs of Indonesia and ASEAN in the middle of their various multilateral agendas? This paper would like to elaborate on the importance of Indonesia's or ASEAN's involvement in the Indo-Pacific by considering real situations, real needs and obstacles to be faced, especially in regards to politics-security challenges.
\end{abstract}

Keywords: Indo-Pacific Phenomenon, Indonesia Diplomacy

\begin{abstract}
Abstrak
Kemunculan terminologi Indo-Pasifik sejak tahun 2007 hingga 2013 yang menguat hingga sekarang telah menciptakan dinamika "ketegangan" baru antar berbagai aktor kawasan. Istilah Indo-Pasifik setidaknya mencerminkan adanya diskursus transformasi geopolitik baru di kawasan antara lautan Hindia dan Pasifik tersebut. Tidak ketinggalan Indonesia dengan posisi strategisnya juga terlibat aktif dalam pengembangan diskursus dan diplomasi Indo-Pasifik. Menimbang luasnya cakupan area geografis konsep Indo-Pasifik dan banyaknya aktor negara termasuk distribusi power dan struktur yang akan terlibat, maka diperlukan analisis komprehensif kritis dalam melihat fenomena Indo-Pasifik. Apa sebenarnya tujuan Indonesia melalui aksi diplomasi Indo-Pasifik? Apakah ada kebutuhan yang sangat mendesak saat ini untuk terlibat dalam isu geopolitik yang sangat luas ini? Apakah Indo-Pasifik menjawab kebutuhan Indonesia dan ASEAN di tengah agenda multilateral yang sudah sedemikian banyak? Paper ini ingin melihat urgensi keterlibatan Indonesia/ASEAN dalam Indo-Pasifik dengan mempertimbangkan situasi dan kebutuhan nyata serta kendala yang akan dihadapi terutama terkait tantangan dimensi politik-keamanan (security).
\end{abstract}

Kata Kunci: Fenomena Indo-Pasifik, Diplomasi Indonesia 


\section{Pendahuluan}

Indo-Pasifik muncul sebagai konsep geografis yang mencakup kawasan Lautan Hindia dan Lautan Pasifik sejak Guurpet S. Kurana menggunakan kata "Indo-Pacific Strategy" pada tahun 2007 sebagai seorang Marine Strategist dan Direktur Eksekutif The New Delhi National Marine Foundation (Kurana 2017). Semenjak itu peta strategis Indo-Pasifik mengalami berbagai perubahan arti dan pemaknaan terutama dengan munculnya kebijakan reformasi dan keterbukan Tiongkok pada 1980-an. Bagi Presiden Donald Trump, konsep "Indo-Pasifik" berarti penarikan kekuatan demokratik seperti India, Australia, Jepang, Australia dan negara Asia lain dalam satu garis front "berhadapan" dengan Tiongkok dalam kerangka baru "perang dingin" (Chen 2018). Sementara itu secara individual, masing-masing negara juga melakukan manuver sesuai dengan perspektif dan kepentingan strategisnya sehingga menimbulkan beragam dinamika baru dalam berbagai forum. Tidak ketinggalan, Indonesia melalui diplomasi Indo-Pasifik secara aktif juga melibatkan diri untuk mensosialisasikan konsep IndoPasifik yang menekankan prinsip inklusivitas, transparansi dan penghormatan kepada hukum internasional (Kompas 2018) termasuk penekanan pada sentralitas ASEAN. Apa sebenarnya yang ingin dicapai Indonesia dan ASEAN dalam diskursus yang melibatkan wilayah dan aktor yang sangat luas dimana negara besar bagian dari 5 P (UN'S Security Council's Five Permanent Members) -- Amerika Serikat, Tiongkok, Rusia - juga terlibat? Apa kepentingan mendesak Indonesia dan ASEAN? Apakah realistis bagi Indonesia/ASEAN saat ini dengan mempertimbangkan berbagai agenda multilateral, kerangka kerja, tantangan politis dan dana untuk merealisasikan diplomasi Indo-Pasifik tersebut? Paper ini ingin melihat secara kritis dan komprehensif urgensi agenda Indo-Pasifik dari perspektif kebutuhan realistis Indonesia dan ASEAN dan sumber daya yang tersedia.

\section{Metode Kajian}

Kajian ini dilaksanakan dengan menggunakan metodologi penelitian kualitatif. Subyek penelitian adalah keterlibatan Indonesia dalam diskursus dan diplomasi Indo-Pasifik sementara obyek penelitian adalah kondisi dan situasi agenda multilateral Indonesia dan ASEAN serta tantangan politik-keamanan dalam dinamika Indo-Pasifik. Kajian juga bersifat deskriptif analitik karena menggambarkan dan menjelaskan situasi geografis regional kawasan dan menganalisis hubungan kausalitas antar variabel yaitu kepentingan dan strategi kebijakan antar berbagai aktor negara. Kajian juga menggunakan pendekatan sosial historis, geografis politis, dimensi keamanan, hubungan multilateral serta perspektif praktisi untuk mendapatkan gambaran nyata konteks kawasan.

Terkait pengumpulan data dilaksanakan dengan berbagai metode, yaitu (i) studi pustaka dan (ii) wawancara. Studi pustaka adalah kegiatan pengumpulan data sekunder yang dilakukan melalui bacaan dari berbagai sumber yaitu berita, opini media, artikel jurnal ilmiah, buku maupun informasi peta. Wawancara dilaksanakan dengan berbagai nara sumber dari Lembaga Ilmu Pengetahuan Indonesia (LIPI), Akademisi Hubungan Internasional dari universitas, praktisi Diplomat Kementerian Luar Negeri Republik Indonesia.

Untuk memperkuat dan melengkapi analisis kajian, penulis juga menggunakan konsep disiplin ilmu sosial lain yaitu Sejarah dan Geografi untuk membantu memperjelas fenomena regionalisme Indo-Pasifik. Dengan demikian pemahaman mengenai fenomena regionalisme Indo-Pasifik akan diperkaya dengan analisis kritis atas data yang terutama bersifat kualitatif dan menjadi sintesa berdasarkan pembacaan dan wawancara dengan nara sumber ahli. 


\section{Apakah Indo-Pasifik?}

Secara biogeografis penyebutan istilah Indo-Pasifik atau Indo-West Pacific atau IndoPacific Asia akan menunjuk suatu area yang sangat luas dari kawasan Hindia hingga Lautan Pasifik bagian barat dan tengah dengan berbagai negara yang ada di dalam kawasan tersebut termasuk negara-negara pantai timur Afrika, Rusia, Asia Selatan, Asia Timur termasuk China, Asia Tenggara, Australia, Amerika Serikat.

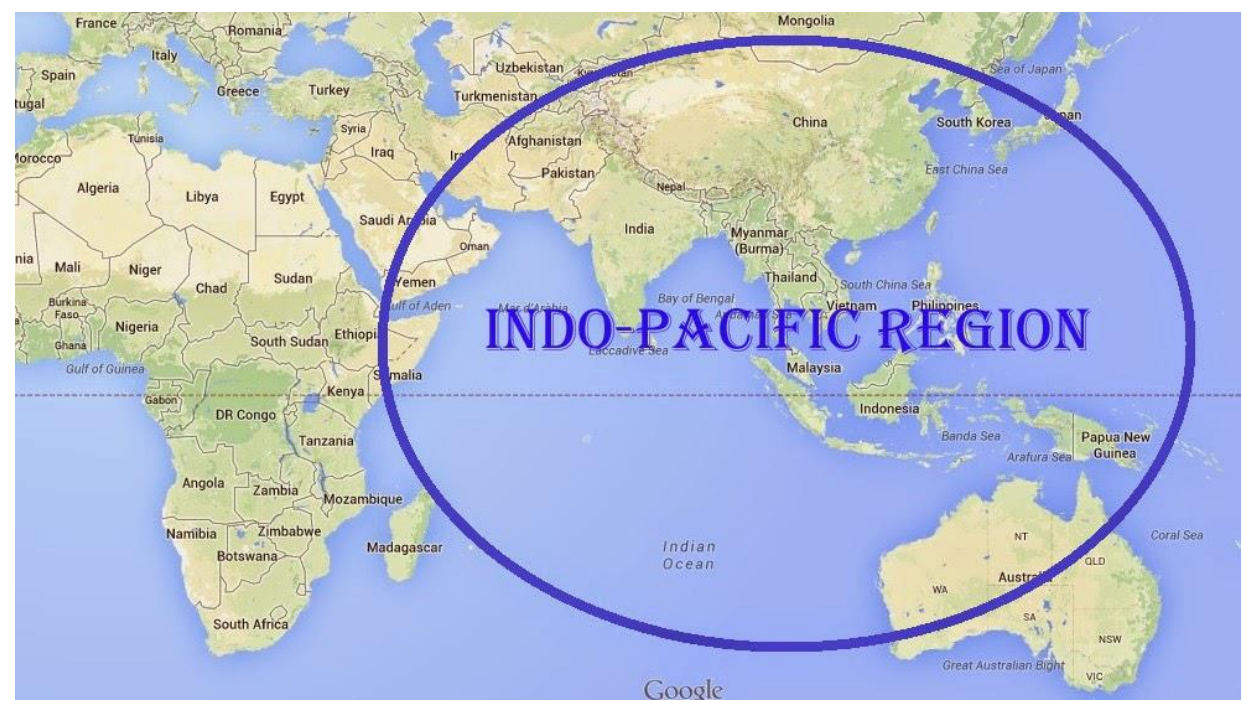

Dari segi konservasi, World Wide Fund dan Nature Conservancy malah membagi kawasan yang disebut Indo-Pasifik dalam 3 area yaitu (i) Indo-Pasifik Tengah termasuk sejumlah laut dan selat yang menghubungkan Samudra Hindia dan Pasifik, termasuk laut di sekitar kepulauan Indonesia, Laut China Selatan, Laut Filipina, pantai utara Australia, laut sekitar New Guinea, Mikronesia barat dan tengah, New Caledonia, Kep Solomon, Vanuatu, Fiji dan Tonga. Karena letaknya sebagai pertemuan dua samudra Indo-Pasifik Tengah mempunyai kekayaan terumbu karang dan mangrove yang besar; (ii) Indo-Pasifik bagian Timur di sekitar kepulauan vulkanik Samudra Pasifik dari Kep. Marshall, Polinesia bagian tengah dan tenggara hingga P. Easter dan Hawaii; dan (iii) Indo-Pasific Barat yang meliputi bagian barat dan tengah Samudra Hindia termasuk pantai timur Afrika, Laut Merah, Teluk Aden, Teluk Persia, Laut Arab, Teluk Bengal dan lautan Andaman termasuk perairan pantai sekitar Madagaskar, Seychelles, Comoros, Kep Mascarene, Maldives dan Kep Chagos.

Dalam konteks geopolitik, tercatat penggunaan istilah "Indo-Pasifik" oleh ahli geopolitik Jerman Karl Haushover pada tahun 1920 dalam tulisan akademiknya yaitu "Indopazifishen Raum". Sejak itu mulai digunakan istilah Indo-Pasifik dalam kontek ekonomi maupun politik-keamanan untuk menunjuk area diantara dua samudra Hindia dan Pasifik. Mulai 2010 konsep Indo-Pasifik menjadi bahan pembicaraan para pembuat kebijakan, analisis maupun akademisi. Meskipun Australia telah menggunakan istilah ini sebelumnya, namun Guurpet S. Kurana (2017) menyatakan bahwa konsep Indo-Pasifik muncul pertamakali dalam paper akademiknya 'Security of Sea Lines: Prospects for India-Japan Cooperation' yang diterbitkan dalam Strategic Analysis Journal of the Insitute for Defence Studies and Analysis (IDSA) New Dehli edisi Januari 2007. Yang dimaksud Indo-Pasifik sebagai konstruksi regional meliputi area Lautan Hindia atau Indian Ocean Region (IOR) hingga kawasan Pasifik 
Barat atau West Pacific Region (WP) termasuk lautan yang saling terhubung di Asia Timur maupun Asia Tenggara, meskipun terdapat berbagai variasi definisi sesuai dengan preferensi negara bersangkutan. Amerika Serikat misalnya cenderung mengartikan Indo-Pasifik sebagai keseluruhan Samudra Hindia dan Pasifik sehingga memungkinnya sebagai negara besar memasukkan pengaruh dalam kawasan tersebut. Meskipun kondisi Lautan Hindia dan Pasifik Barat sangat berlainan namun dengan mulai meningkatnya kegiatan ekonomi di kawasan maritim Asia dari Afrika Timur hingga Asia Timur termasuk Proliferation Security Initiative (PSI) oleh Amerika Serikat pada 2004 - maka mulai dibutuhkan suatu nomenklatur regional bersama yang sesuai untuk komunikasi yang efektif (Kurana 2017).

Seperti diketahui, IOR dan WP sangat berbeda dalam semua aspek baik tingkat pertumbuhan negara-negara sekitarnya, parameter sosialnya maupun keamanan lingkungannya. Tidak seperti IOR, WP berada dalam kondisi ancaman militer tradisional sesuai dengan faktor historis yang melingkupinya terutama sejak abad 21 yaitu kekuatan militer negara besar seperti Jepang, Tiongkok termasuk usaha-usaha teritorialisasi kelautannya. Dominasi militer merupakan konsekuensi dari kemajuan ekonomi yang kemudian menarik negara-negara sekitarnya (Korea, Taiwan, Hongkong, Singapura) dan sering digambarkan sebagai paradigma "flying geese". (Kurana 2017: 1). Sementara IOR tidak mengalami dominasi negara besar. Meskipun dari segi sumber daya (hidrokarbon) kaya, namun negara-negara IOR umumnya kurang berkembang secara ekonomi. Selain faktor kolonialisme yang telah berlangung lama, keberagaman mereka kurang mendukung integrasi perkembangan ekonomi. Tidak ada negara yang cukup kuat mengatur lingkungan regional IOR dan mengembangkan kapasitas militer untuk mendominasi negara lain. Masalah keamanan non-tradisional lebih dominan dihadapi oleh IOR misalnya bajak laut, illegal fishing, penyelundupan narkotika dan manusia serta masalah imigrasi.

Sementara PSI adalah suatu usaha global untuk menghentikan pengiriman senjata pemusnah masal, sistem pengirimannya dan bahan-bahan/material yang terkait dari negara maupun aktor non-negara yang terlibat. PSI dibentuk pada 31 Mei 2003 dimana Amerika Serikat mulai terlibat yang dimulai dari inisiatif Amerika melalui US National Strategy to Combat Weapons of Mass Destruction yang diumumkan pada Desember 2002. Strategi ini mengakui perlunya sarana yang lebih andal untuk menghentikan peningkatan WMD (Weapons of Mass Destruction) di seluruh dunia dan secara khusus mengidentifikasi interdiksi sebagai area untuk memperluas fokus pengawasan. Presiden Obama pada waktu itu sangat mendukung PSI dan pada April 2009 melalui pidato di Praha meminta PSI untuk terus melakukan usaha penurunan WMD internasional dan menekankan sebagai posisi Pemerintah AS yang formal dalam dokumen kebijakan AS, termasuk White House's National Security Strategy and the Pentagon's Quadrennial Defense Review.

Akan halnya penyebutan "Asia" dirasa terlalu luas, heterogen dan berkonotasi kontinenal daripada maritim, sementara sebutan "Asia Pasifik" - yang menunjuk bagian Asia di Samudra Pasifik terasa tidak memadai. Sebutan "Indo-Pacific" (gabungan dari Indian Ocean dan Pacific Ocean) dirasa memadai/mewakili kebutuhan tersebut. Penyebutan IndoPasifik juga tidak terlepas dari meningkatnya posisi superioritas India memasuki abad 21 ditandai dengan pertumbuhan ekonomi India yang impresif pada dekade 1990-an dan pengembangan senjata nuklirnya. Kebangkitan India menjadi faktor kunci dalam meningkatnya signifikansi Samudra Hindia dan India tidak dapat lagi diabaikan dalam pembicaraan ekonomi maupun politik terkait kawasan Asia Pasifik. (Kurana 2017:3). Pengakuan akan pentingnya posisi India nampak dalam keterlibatan dalam ASEAN Regional Forum (1996) dan East Asia Sumit (2005) serta partisipan kunci dalam PACOM (US IndoPacific Command atau USINDOPACOM). Konsep Indo-Pasifik sendiri mampu mengatasi "perasaan di luar/tidak inklusif" (sense of exclusion) India ketika harus terlibat dalam 
membicarakan masalah-masalah maritim Asia Pasifik. Aspek penting lain keterhubungan IOR dan WP adalah adanya kekayaan hydrocarbon yang akan mendorong kesejahteraan negaranegara kepulauan sekitar Pasifik.

Perkembangan konsep Indo-Pasifik juga sangat diwarnai oleh kepentingan Jepang akan kebutuhan jaminan keamanan transportasi laut, mengingat Jepang sangat tergantung pada energi dan impor makanan melalui jalur IOR. Untuk memperkuat peran keamanan maritim, Jepang membangun hubungan kerja sama dengan India dan semakin jelas bahwa penanganan di IOR dan WP tidak dapat dipisahkan. Sikap Jepang diperjelas dengan pidato PM Shinzo Abe di depan Parlemen India (2007) mengenai ""Confluence of the Indian and Pacific Oceans" as "the dynamic coupling as seas of freedom and of prosperity" in the "broader Asia". (Kurana 2017: 4). Pesan PM Shinzo menggaris bawahi kepentingan Jepang dan signifikansi India dalam mempertahankan kepentingan tersebut, yang diformulasikan dalam penyatuan term geopolitik "Indo-Pasifik".

\footnotetext{
"The Pacific and the Indian Oceans are now bringing about a dynamic coupling as seas of freedom and of prosperity. A "broader Asia" that broke away geographical boundaries is now beginning to take on a distinct form. Our two countries have the ability -- and the responsibility - to ensure that it broadens yet further and to nurture and enrich these seas to become seas of clearest transparence."
}

Sedemikian pentingnya peran India dalam kepentingan geopolitik Jepang sehingga PM Shinzo Abe menawarkan suatu "Strategic Global Partnership" dimana dua pihak akan memperluas dan meningkatkan hubungan mereka. Jepang sangat menghargai kontribusi India dalam sejarah dunia yaitu semangat nilai-nilai toleransi serta tantangan yang dihadapi yaitu besarnya jumlah penduduk, pergerakan demografis ke kota dan kemiskinan. Perwujudan dari Strategic Global Partnership adalah peningkatan hubungan perdagangan melalui keterlibatan perusahaan-perusahaan Jepang, bantuan ODA (Official Development Assistance) untuk reboisasi dan pengadaan air serta pertukaran kaum muda India ke Jepang antara lain untuk mempelajari bahasa dan pengajaran bahasa Jepang.

Pada 2010 Amerika Serikat untuk pertama kalinya mengakui secara resmi konsep Indo-Pasifik melalui pidato Hillary Rodham Clinton sebagai Secretary State pada 28 Oktober 2010 di Hawai. Kunjungan tersebut dalam rangka perjalanan ke berbagai negara Asia Pasifik (Hawai, Guam, Vietnam, Kamboja, Malaysia, Papua New Guinea, New Zealand, Australia dan Samoa-Amerika) - untuk melengkapi kunjungan Presiden Obama ke India, Indonesia, Jepang, dan Korea Selatan. Kebijakan pemerintah Obama pada saat itu adalah "American engagement" di kawasan Asia Pasifik melalui "forward-deployed" diplomacy yaitu mengaplikasikan a very proactive footing dengan mengirim aset diplomatik secara penuh termasuk pejabat tinggi, ahli pembangunan dan tim untuk berbagai isu -- karena melihat pertumbuhan transformasi ekonomi yang sangat besar dimana Asia menjadi pusat bisnis dan perdagangan dan tumbuhnya generasi masa depan di berbagai bidang (bisnis, teknologi, politik, seni). Tiga ranah yang ditekankan AS adalah (i) membentuk masa depan ekonomi Asia Pasifik, (ii) menjamin keamanan regional dan (iii) mendukung lembaga demokratik menjadi lebih kuat serta menyebarkan nilai-nilai hak-hak asasi manusia universal termasuk aktivitas militer 3D (defense, diplomacy, development).

Pendekatan yang digunakan diawali dengan pertemuan bersama para sekutu Asia Pasifik, yaitu Jepang, Korea, Australia, Thailand dan Filipina yang menjadi dasar strategic engagement Amerika. Selain memperbaharui hubungan dengan 5 aliansinya, AS juga memperkuat dengan partner barunya yaitu Indonesia - sebagai pemimpin ASEAN dan Bali Democratic Forum - termasuk akan menerbitkan Comprehensive Partnership Agreement dengan Vietnam, Singapura, Malaysia dan New Zealand. Selain itu, AS juga mengakui dinamika baru dengan tumbuhnya Tiongkok dan India. Sementara itu Australia pada 2013 
mengakui kebijakan India yang berorientasi ke timur (eastwest orientation). Dalam Defense White Paper (WP) atau Buku Putih Petahanannya, Australia menyatakan kepentingan strategik yang sama dengan India di kawasan Indo-Pasifik. Strategi Indo-Pasifik baru ini dipandang bisa menghubungkan Samudra Hindia dan Pasifik melalui Asia Tenggara. Kerangka baru ini didorong oleh beberapa faktor yaitu pertumbuhan perdagangan yang masif, energi dan aliran investasi antara Asia Timur dan Samudra Hindia dan meningkatnya India sebagai kekuatan strategis, ekonomi dan diplomatik yang penting di Asia Selatan. Pada intinya Australia melakukan pergeseran strategi ekonomi dan militer ke Indo-Pasifik. Sementara dalam WP 2016 Australia menekankan kawasan Indo-Pasifik yang stabil dan mendasarkan diri pada aturan tatanan global. Pada 2013 pejabat AS mulai menggunakan istilah "Indo-Asia Pasifik" yang memungkinkan AS untuk mempertahankan inklusivitasnya dalam "Indo-Pasifik". Profil istilah tersebut muncul dalam pernyataan bersama antara PM Narendra Modi dan Presiden AS Donald Trump sesudah kunjungan kenegaraan PM Modi ke Gedung Putih pada 26 Juni 2017:

\begin{abstract}
"In marking 70 years of diplomatic relations between India and the United States, the leaders resolved to expand and deepen the strategic partnership between the countries and advance common objectives. Above all, these objectives include combatting terrorist threats, promoting stability across the Indo-Pacific region, increasing free and fair trade, and strengthening energy linkages."
\end{abstract}

Bagi Rusia, Indo-Pasifik konsep dirasa melengkapi konsep Greater Eurasia dimana skema Indo-Pasifik akan mengarahkan Rusia ke tenggara hingga Australia dan Selandia Baru demi meningkatkan konektivitas regional.

\begin{abstract}
"For the Russian Far East, the Indo-Pacific is a chance to make a leap into the future. In terms of Greater Eurasia, it is projected as Russia's gateway to the East. For the IPR, it is its northern gateway, through which Arctic resources will flow to Asia. The unique geopolitical location at the meeting point of sea and land, Greater Eurasia and IPR, is what can give a new impetus to the development of the Russian Far East."
\end{abstract}

\title{
4. Urgensi Diplomasi Indo-Pasifik Indonesia
}

Dalam diskursus Indo-Pasifik pemerintah Indonesia terlihat sangat aktif menyuarakan konsepnya dan menjadi bagian agenda penting perumusan politik luar negeri Indonesia. Diplomasi Indonesia di berbagai forum semenjak 2013 menunjukkan inisiatif Indonesia dan "positioning" Indonesia tidak hanya di kawasan ASEAN namun juga dalam konstruk geostrategik baru di kawasan Indo-Pasifik dimana Indonesia dianggap mulai memperluas skope lingkaran konsentriknya hingga Samudra Hindia dan bahkan dapat dilihat sebagai signaling emerging power (Shekhar 2018: 26).

Sepanjang tahun 2018, konsep Indo-Pasifik telah beberapa kali dikomunikasikan; antara lain dalam forum pertemuan Menteri Luar Negeri ASEAN ke-51 dan Post Ministerial Conference ke-19 yang diselenggarakan pada 31 Juli - 4 Agustus 2018 oleh Menteri LN RI Retno Marsudi. Bahkan dalam KTT ke-33 ASEAN Presiden Jokowi menyatakan mengenai pentingnya konsep Indo-Pasifik dan sentralitas ASEAN sementara pada KTT ke 32 April 2018 Presiden juga menekankan pentingnya ASEAN mengembangkan kerja sama di kawasan Indo-Pasifik yang mengedepankan prinsip-prinsip keterbukaan, inklusivitas, transparansi, menghormati hukum internasional, dan menghargai sentralitas ASEAN.

Namun di tengah antusiasme ini, sebagai suatu konsep operasional, "Indo-Pasifik" harus diakui sebagai sesuatu yang "belum jelas". Pengakuan Menteri LN Indonesia atas perlunya waktu dan belum jelasnya target realisasi menunjukkan "jalan panjang" yang masih 
harus ditempuh Indonesia. Sikap Tiongkok yang secara serius mempertanyakan konsep Indo-Pasifik Indonesia untuk diadopsi ASEAN juga dapat menjadi indikasi "perbedaanperbedaan fundamental" dalam penerimaan dan penyatuan konsep ini.

Dengan kata lain ada beberapa hal yang perlu dipertimbangkan dalam inisiatif IndoPasifik untuk menentukan urgensinya, yaitu pertama "Indo-Pasifik" adalah konsep yang sifatnya "reaktif" dari Amerika Serikat dan sekutunya untuk "mengkounter" kebangkitan Tiongkok menuju status Super Power (baru) terutama melalui strategi One Belt One Road (OBOR) atau Belt and Road Initiative (BRI) yang diproklamirkan pertama kali oleh Presiden Xi Jinping di Kazakhstan September 2013. Pada intinya BRI adalah pengembangan jalur sutera ekonomi melalui (i) Tiongkok-Asia Tengah-Rusia-Eropa, (ii) Tiongkok-Asia TengahAsia Barat-Teluk Persia, (iii) Tiongkok-Asia Selatan-Asia Tenggara-Lautan Hindia serta pengembangan jalur maritim abad 21 yang meliputi (i) Pantai Tiongkok - Laut Tiongkok Selatan - Lautan Hindia- Eropa dan (ii) Pantai Tiongkok - Laut Tiongkok Selatan - Pasifik Selatan. BRI akan menghubungkan lebih dari 65 negara mencakup sekitar $62 \%$ penduduk dunia, 35\% perdagangan dunia dan 31\% GDP dunia. (Tenggara Strategic 2018, Bambang Cipto 2018: 26-31). Karena hakekatnya merupakan "kompetisi politik" maka jelas ini merupakan area dengan dimensi keamanan yang kompleks - karena akan menyangkut kepentingan dan strategi setiap negara. Dimensi keamanan (security) sulit diselesaikan karena kepentingan politis setiap negara tidak mudah dipertemukan dan lebih banyak "pembelahan" (division) daripada penyatuan serta dapat dipastikan akan banyak "deadlock" dalam pertemuan.

Kedua, kawasan Indo-Pacifik adalah kawasan yang amat luas yang melibatkan berbagai aktor baru serta negara-negara besar (Amerika, Tiongkok, Rusia, India) dengan kepentingan masing-masing yang sangat kuat. Kawasan ini melebihi luasnya ASEAN (10 negara) dan ASEAN Plus yang biasa dihadapi Indonesia. Dengan masuknya aktor baru yang belum tentu compatible mungkinkan Indo-Pasifik merupakan proyek yang mudah dilaksanakan?

Ketiga, apa sebenarnya tujuan Indonesia? Apakah ada kebutuhan nyata dan mendesak (urgent) dari Indonesia untuk masuk dalam regionalisme Indo-Pasifik yang sangat besar ini? Lebih besar dari cakupan kawasan ASEAN Plus, APEC (Asia Pacific Economic Cooperation), IORA (Indian Ocena Rim Association) dan seterusnya. Apa yang Indonesia butuhkan? Jika kebutuhan lebih pada dimensi ekonomi bukankah sudah terfasilitasi dalam ASEAN Plus, G7 (Group of Seven adalah kelompok negara ekonomi maju menurut IMF yang terdiri dari Kanada, Perancis, Jerman, Italia, Jepang, Inggris dan Amerika Serikat), APEC (Asia-Pacific Economic Cooperation) dan sebagainya? Apakah kita akan membangun sesuatu yang tidak realistis dan menggunakan sumber daya diplomasi yang ada untuk suatu tujuan yang tidak mendesak? Jika kita melihat agenda ASEAN dengan Mitra Wicara Penuhnya (ASEAN-AS, ASEAN-Australia, ASEAN-Tiongkok, ASEAN-India, ASEAN-Jepang, ASEAN-Kanada, ASEAN-Republik Korea, ASEAN-Rusia, ASEAN-Selandia Baru, ASEANUni Eropa), ASEAN plus Three (APT), KTT Asia Timur dan kerja sama dengan Mitra Wicara Sektoral, sebenarnya Indonesia/ASEAN sudah mempunyai agenda yang sangat banyak - mengingat mekanisme di dalamnya sudah berjalan dan terus menerus menghasilkan perkembangan masalah yang harus dibahas dan ditindaklanjuti.

Seperti kita ketahui, mekanisme hubungan ASEAN dengan mitra wicara biasanya dilaksanakan melalui beberapa tahapan (i) Pada tingkat Kepala Negara dilakukan melalui KTT ASEAN dan KTT terkait lainnya, (ii) Pada tingkat Menteri dilakukan melalui pertemuan tingkat menteri ASEAN (ASEAN Ministerial Meeting/AMM), pertemuan dengan mitra wicara (Post Ministerial Conference/PMC) dan pertemuan tingkat menteri di luar rangkaian PMC, (iii) Pada tingkat Pejabat Tinggi ASEAN (Senior Officials Meeting/SOM), mitra 
wicara dan pertemuan di luar rangkaian SOM seperti Senior Officials Consultations/SOC, Forum dan Consultation among Senior Officials, (iv) Pada tingkat Direktur Jenderal seperti Working Group/WG, Joint Cooperation Committee/JCC, Joint Planning Committee/JPC dan Japan-ASEAN Integration Fund/JAIF Management Committee/JMC), (v) Pada tingkat kelompok ahli, (vi) Pada tingkat sektoral, (vii) Pada tingkat Komite Wakil Tetap (Committee of Permanent Representatives/CPR). (DirJen Kerjasama ASEAN, 2010).

Keempat, di kawasan Indo-Pasifik Indonesia akan menghadapi tantangan terkait "budaya kerja sama" dan "mindset". Asia Selatan misalnya boleh dikata tidak mempunyai budaya kebersamaan/kerja sama (togetherness culture). Regionalisme di Asia Selatan tidak berkembang cukup baik. ASEAN dapat bertahan hingga kini karena mempunyai tekad menciptakan suasana kondusif untuk membangun, tidak saling mendominasi dan mencegah usaha politisasi forum ( misalnya dalam kasus APEC). Tantangan "mindset" akan dihadapi terutama dengan Tiongkok. Tiongkok dalam posisi sekarang adalah Tiongkok yang mempunyai norma sendiri (tidak tunduk pada norma internasional) dan obsesif untuk meraih "kejayaan" (gloriness) terbukti dalam perilaku geopolitik (geopolitical code) Tiongkok di Laut Tiongkok Selatan maupun bantuan ekonomi BRI (Belt and Road Initiative) bagi negaranegara sedang berkembang di Asia Selatan seperti Srilanka. Apakah tantangan ini siap dihadapi Indonesia dalam diplomasi Indo Pasifik?

Kelima, setiap usaha mempromosikan suatu ide akan dituntut dengan realisasi dan setiap realisasi membutuhkan dana. Jika pada forum ASEAN plus 3 misalnya dana dapat diperoleh dari para mitra, maka dalam diskursus Indo-Pasifik sumber dana masih belum jelas. Peluang dana sangat mungkin diperoleh dengan catatan bahwa pengembangan isu dengan bobot sangat politis akan menimbulkan implikasi kontra produktif dimana penerimaan dana dari salah satu negara besar akan bertentangan dengan prinsip non blok ASEAN.

\section{Kesimpulan}

Semangat diplomasi Indo-Pasifik Indonesia patut dihargai sebagai bagian dari dorongan untuk menciptakan stabilitas dan keamanan kawasan. Namun usaha ini perlu dilihat secara komprehensif dan kritis terutama terkait kebutuhan, tujuan dan urgensi. Bobot politis yang sangat besar dalam regionalisme Indo-Pasifik akan mendorong Indonesia masuk dalam dimensi keamanan (security) yang tidak mudah dihadapi selain mekanismenya (vehicles) yang belum tersedia. Disamping itu, Indonesia dan ASEAN sudah mempunyai berbagai mekanisme dan kerja sama yang telah melibatkan negara-negara besar yang lebih berdimensi pembangunan sosial ekonomi (development/trade) terutama melalui berbagai kerja sama dengan mitra wicara, ASEAN Plus dan sebagainya yang sudah dibangun dan terbukti sejauh ini berjalan dengan baik. Indo-Pasifik akan menemukan urgensi dalam politik luar negeri dan diplomasi Indonesia jika Indonesia dapat menemukan apa "kebutuhan paling mendasar" dalam proyek Indo-Pasifik. 


\section{DAFTAR PUSTAKA}

\section{Buku}

Cipto , Bambang. Hubungan Internasional di Asia Tenggara Teropong terhadap Dinamika, Kondisi Riil dan Masa Depan. Yogyakarta: Pustaka Pelajar, 2007.

Cipto, Bambang. Strategi China Merebut Status Super Power. Yogyakarta: Pustaka Pelajar, 2018

Direktorat Kerja Sama ASEAN. ASEAN Selayang Pandang Edisi ke-19. Jakarta: Direktorat Jenderal Kerjasama ASEAN, Kementerian Luar Negeri Republik Indonesia, 2011.

Ibrahim, Erlangga, and Syahrizal Budi Putranto. Jalur Sutera Bagian I: China Perjalanan dari Xi'an ke Kahgar. Jakarta: PT Batara Ahara Nusa, 2011.

Jacques, Martin. When China Rules the World. Kebangkitan Dunia Timur dan Akhir Dunia Barat. Jakarta: Buku Kompas, 2011.

Kaplan, Robert D. The Revenge of Geography. New York: The Random House Trade Paperbacks, 2013.

Medcalf, Rory. The Indian EXPRESS. May 10, 2013. http://archive.indianexpress.com/news/the-indopacific-pivot/1113736 (accessed 2019).

Naisbitt, John, and Doris. China's Megatrends. Jakarta: Gramedia Pustaka Utama, 2010.

Shekhar, Vibhanshu. Indonesia's Foreign Policy and Grand Strategy in The 21st Century: Rise of Indo-Pacific Power. Abingdon: Routledge, 2018.

Tenggara Strategics. Belt and Road Intiative (BRI): What's in it for Indonesia. Outlook, Jakarta: Tenggara Strategics, 2018.

\section{Surat Kabar}

Koestanto, Benny D. Kompas. Geopolitik Asia Pasifik: Indonesia di Tengah Pusaran IndoPasifik. December 2, 2018.

\section{Website}

Chen, Dingding. ISPI. June 04, 2018. https://www.ispionline.it/it/pubblicazione/indo-pacificstrategy-background-analysis-20714 (accessed 2019).

H.E. Mr. Shinzo Abe. Ministry of Foreign Affairs of Japan. August 22, 2007. https://www.mofa.go.jp/region/asia-paci/pmv0708/speech-2.html (accessed 2019).

Khurana, Gurpreet S. CIMSEC. November 14, 2017. http://cimsec.org/indo-pacific-conceptretrospect-prospect/34710 (accessed 2019).

Kuo, Mercy A. The Diplomat. January 25, 2018. https://thediplomat.com/2018/01/the-originof-indo-pacific-as-geopolitical-construct/ (accessed 2019).

Laksmana, Evan A. Brookings. November 27, 2018. https://www.brookings.edu/blog/orderfrom-chaos/2018/11/27/buck-passing-from-behind-indonesias-foreign-policy-and-theindo-pacific/ (accessed 2019).

Medcalf, Rory. The Indian EXPRESS. May 10, 2013. http://archive.indianexpress.com/news/the-indopacific-pivot/1113736 (accessed 2019).

Tham, Jansen. The Diplomat. May 16, 2018. https://thediplomat.com/2018/05/whats-inindonesias-indo-pacific-cooperation-concept/ (accessed 2019).

U.S. Indo-Pacific Command. UNISDOPACOm Area Of Responbity. n.d. https://www.pacom.mil (accessed 2019). 